\title{
A Method for Setting the Artificial Boundary Conditions of Groundwater Model
}

\author{
Yipeng Zhou ${ }^{1,2}$, Zhaoli Shen ${ }^{1}$, Weijun Shi ${ }^{2}$, Jinhui Liu ${ }^{2}$, Yajie Liu ${ }^{2}$ \\ ${ }^{1}$ School of Water Resources and Environment, China University of Geosciences, Beijing, China \\ ${ }^{2}$ Department of Civil and Environmental Engineering, East China Institute of Technology, Nanchang, China \\ Email: zyp721@163.com, wjshiecit@163.com
}

Received 2013

\begin{abstract}
Numerical simulation technology is nowadays an important means for groundwater issues because of its efficiency and economical advantages. But in case of natural hydrogeological boundaries are not within the interest area, it may be a big trouble to set boundary conditions of the model artificially without enough field investigation information. This paper introduced a method for solving such problem applying field pumping test and recovery test. The method was applied to build an in-situ leaching of uranium model. Results showed that the model boundary conditions can be set satisfactorily, and also the calculated heads matched the observed data well in both two models.
\end{abstract}

Keywords: Groundwater; Numerical Model; Artificial Boundary Conditions

\section{Introduction}

Since the 1960s, with the development of computer technology, the method of numerical simulation had been widely used to solve groundwater flow and solute transport problems because of its effectiveness, flexibility and relatively economical with spend, and gradually become an important method for groundwater issues [1-7]. However, although lots of models have been built in various applications, few people care about the real effects of those models in practices [8]. One of important factors influencing the reliability of the groundwater model is geology and hydrogeology investigation; and usually making reasonable understandings on boundary conditions is a big challenge [9]. Once the boundary conditions are distorted to the truth, it is bound to lead to significant deviation of the model calibration parameters from actual values, and then serious impact on the reliability of the model would not be avoided.

Model boundary conditions are usually set according to field investigations. When the interest area is small that the model boundaries are far away from natural hydrogeological boundaries, artificial model boundary conditions need to be set according to a long-term observation of groundwater at those boundaries. However, in many cases, the required observation data are often unavailable; in this dilemma, one alternative way is to expand model extent so that the groundwater can be assumed not to be affected by human activities (such as pumping test) taken placed in the interest area; then the boundary conditions of first type or of second type can be set at model's boundaries [9]. But this kind of solution also has shortcomings, one of which is that to establish of model hydrogeology configuration beyond the interest area without supplementary geology investigation information may bring unexpected serious error to the simulation results $[10,11]$. In this paper, in order to build a flow model of groundwater and leaching solution during insitu leaching of uranium process, a method has been employed to set artificial model boundaries by combining theoretical calculation according groundwater unsteady flow theory and the model iterative calibration using observation data of pumping test and recovery test independently.

\section{Methods}

\subsection{Basic Principles}

The basic principle is using field pumping test and recovery test to calibrate the model parameters and boundary conditions simultaneously. First, get the head drawdown function derived from Jacob formula of groundwater unsteady flow at the boundaries located within the cone depression; Then set initial heads generalized from the head drawdown function of the model boundaries for model building and calibration; finally, calibrate model parameters and boundary conditions iteratively using the observation data of pumping test and recovery test independently and then make the results fit the facts to the most degree. 


\subsection{Functions of the Model Boundary Heads}

During pumping test in the confined aquifer, draw down lead to the formation of the cone of depression of pressure head. The range of cone expands continuously with pumping, and gradually achieves a relative stable state. When the whole model is located within the cone, heads at model boundaries would vary with time; so obviously, model boundary conditions need to be set according to head changes. Therefore, the function of head variation must be got at first.

According to the theory of confined water's unsteady flow towards to fully penetrating well, the variation of the head drawdown within pumping influence scope can be approximately described by Jacob Formula [12], as in

$$
s=\frac{Q}{4 \pi T} \ln \frac{2.25 T t}{r^{2} \mu^{*}}
$$

where $s$ is the head drawdown; $Q$ is the pumping rate; $T$ is the coefficient of transmissibility; $t$ is the pumping time; $r$ is the distance to pumping well; $\mu *$ is the coefficient of storage.

Thus, the live head can be calculated via Equation (2):

$$
\left.H(r, t)\right|_{S}=H\left(r, t_{0}\right)-s(r, t)
$$

where $\left.H(r, t)\right|_{S}$ is the head at the point with the distance of $r$ to the pumping well and at the time of $t$; $H\left(r, t_{0}\right)$ is the initial head at the point with the distance of $r$ to the pumping well; $s(r, t)$ is the head drawdown at the point with the distance of $r$ to the pumping well and at the time of $t$.

Since in Equation (2) the head is a continuity function of time, it can not to be applied to set model boundary conditions yet; it need to be temporally discretized to $n$ periods, and in each period the head is a constant, thus, the variation of the head drawdown can be described by Equation (3):

$$
s(r, t)=\left\{\begin{array}{l}
s_{1}, t_{0} \leq t<t_{1} \\
s_{2}, t_{1} \leq t<t_{2} \\
\cdots \cdots \\
s_{n}, t_{n-1} \leq t \leq t_{n}
\end{array}\right.
$$

So, the live head anywhere within the cone of depression during pumping test can be given by the piecewise constant function as Equation (4):

$$
\left.H(r, t)\right|_{S}= \begin{cases}H\left(r, t_{0}\right)-s_{1}, & t_{0} \leq t<t_{1} \\ H\left(r, t_{0}\right)-s_{2}, & t_{1} \leq t<t_{2} \\ \cdots \cdots & \\ H\left(r, t_{0}\right)-s_{n}, & t_{n-1} \leq t \leq t_{n}\end{cases}
$$

Divide the simulation time to $n$ stress periods, and in each period set the model boundary head according to the corresponding constant value of each definition domain of the function shown in Equation (4).

\subsection{Calibrations of the Model Boundary Conditions}

After initial boundary conditions being set through the theoretical calculation mentioned above, run the model to calibrate boundary conditions and parameters iteratively using observation data of the pumping test and recovery test independently. The flow chart of the calibration process is shown in Figure 1.

First, build groundwater flow model of the pumping test and set the model initial boundary conditions for iteration according to Equation (4).

Then, run the model built in the former step to calibrate model parameters and boundary conditions by the observation data of the pumping test. If the standard error of estimate (S.E.E) exceeds 5\%, the hydrogeology parameters and boundary conditions would be adjusted slightly and then the calibration repeats. When the S.E.E is below 5\%, the calibration process goes to the next step.

Finally, build groundwater model of the recovery test applying the calibration results of the second step as initial state; run it to calibrate model parameters and boundary conditions again using the observation data of the recovery test. The S.E.E of $5 \%$ also is applied as calibration error criterion; if results meet the criterion, the calibration process ends and the model parameters and boundary conditions are fixed; otherwise, return to the first step, modify the model parameters and boundary conditions and then the whole process repeats again.

\section{Application Example}

\subsection{Backgrounds and Model Overview}

The study was conducted at the piedmont alluvial slope in the southern region of the Turpan-Hami basin. The

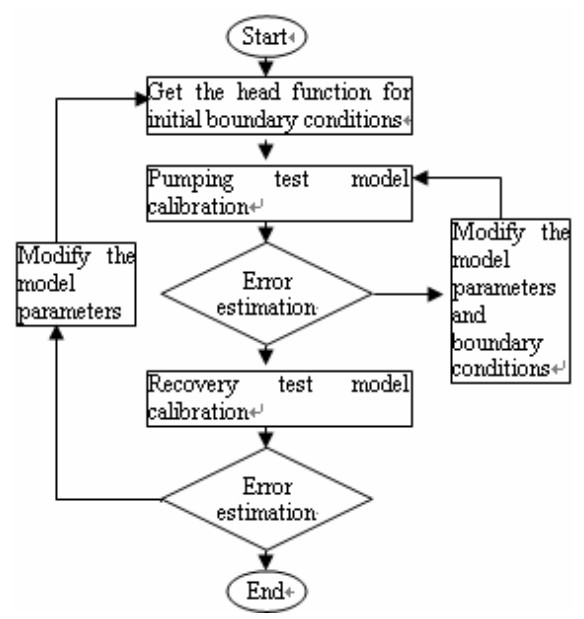

Figure 1. Flow chart of the model calibration process. 
interest confined groundwater system has stable impervious roof and base; the groundwater flew from southwest to northeast with a hydraulic gradient of 0.02 , and was mainly recharged indirectly by the Quaternary phreatic water from the southern mountainous bedrock fissure. The studied issue was about simulation of groundwater and leaching solution flow in the ore-bearing aquifer at an in-situ leaching of uranium site. There are five wells (Figure 2); the well CK1 was for extraction, and the rests were for leaching solution injection.

The hydrogeology characteristic of the aquifer within the mining scope is as shown in Figure 3. The average thickness of the aquifer is about $40 \mathrm{~m}$; the stable impervious roof and base are mainly of mudstone and silty mudstone (in gray); in the aquifer (in blue) there are four discontinuous interlayer, one is of silty mudstone (shown in gray) with the thickness of 1 - 3 meters, and the three others are of calcareous sandstone with the thickness of 0.3 - $0.9 \mathrm{~m}$ (in white).

Field pumping test and recovery test were conducted employing well CK1 for pumping, well ZK1 and well ZK3 for observation, the test results are shown in Table 1.

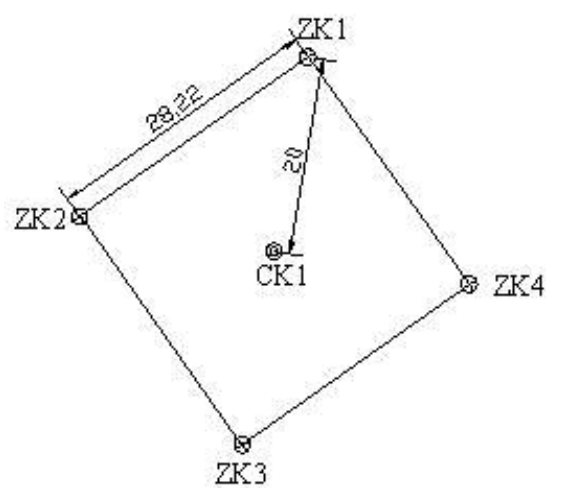

Figure 2. The plan view of well distribution.

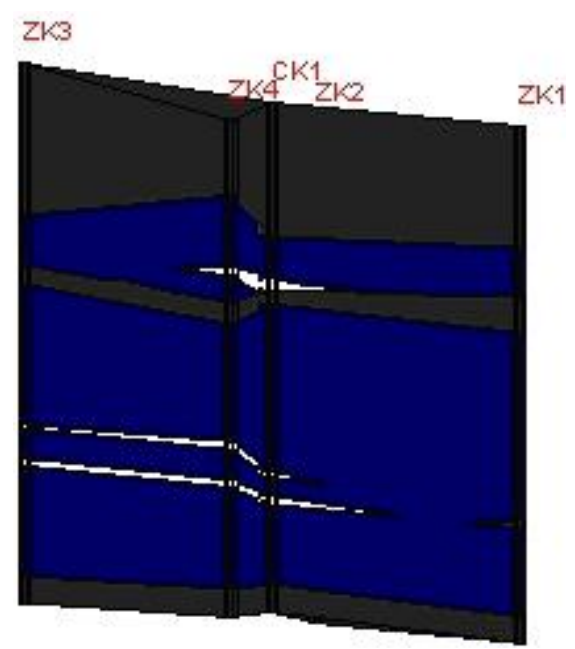

Figure 3. Cross section of the aquifer.
Table 1 field tests and the hydraulic parameters of the aquifer.

\begin{tabular}{ccccc}
\hline Field test & $\begin{array}{c}\text { Test } \\
\text { time } \\
(\mathrm{min})\end{array}$ & $\begin{array}{c}\text { Pumping } \\
\text { rate } \\
\left(\mathrm{m}^{3} / \mathrm{h}\right)\end{array}$ & $\begin{array}{c}\text { Coefficient of } \\
\text { transmissibility } \\
\left(\mathrm{m}^{2} / \mathrm{d}\right)\end{array}$ & $\begin{array}{c}\text { coefficient } \\
\text { of storage }\end{array}$ \\
\hline Pumping test & 2900 & 7.2 & 0.57 & $1.95 \times 10^{-4}$ \\
Recovery test & 2770 & - & & \\
\hline
\end{tabular}

Based on those field investigations, the conceptual model of the groundwater flow during the pumping test was built as Equation (5):

$$
\begin{aligned}
& \frac{\partial}{\partial x}\left(K_{x x} \frac{\partial H}{\partial x}\right)+\frac{\partial}{\partial y}\left(K_{y y} \frac{\partial H}{\partial y}\right)+\frac{\partial}{\partial z}\left(K_{z z} \frac{\partial H}{\partial z}\right)-W \\
& =S_{s} \frac{\partial H}{\partial t},(x, y, z) \in D, t \geq 0 \\
& H(x, y, z, o)=H_{0}(x, y, z) \quad(x, y, z) \in D \\
& \left.H(x, y, z, t)\right|_{S}=f(x, y, z, t) \quad(x, y, z) \in S
\end{aligned}
$$

where $K_{x x}, K_{y y}$ and $K_{z z}$ are respectively the conductivities in $\mathrm{x}, \mathrm{y}$ and $\mathrm{z}$ direction in the three-dimension space; $H$ is the confined water head; $W$ is the flux rate per unit volume, which is used to describe the flow rate of wells; $S s$ is the specific storativity; $t$ is the time; $H_{0}(x, y, z)$ is the initial head at position with the coordinate $(x, y, z)$; $\left.H(x, y, z, t)\right|_{S}$ is the head at the model boundary. The model area denoted $D$ and boundary $S$.

The initial head of $H_{0}(x, y, z)$ was set according to static water level observed at the beginning of the pumping test. Since the modeling area was small, its edges are far away from the natural hydraulic boundaries known, hence artificial boundaries were necessary. A circle surrounding the well CK1 and with radius of 100 meters was set as the boundary of the model.

\subsection{Head Functions of the Model Boundary}

In case of the coefficient of transmissibility is $5.7 \mathrm{~m}^{2} / \mathrm{d}$, the coefficient of storage is $1.95 \times 10^{-4}$ and the pumping rate is $7.2 \mathrm{~m}^{3} / \mathrm{h}$, the radius of influence of the pumping test is more than 800 meters; clearly, the heads at the pumping test model boundaries which were 100 meters away from the pumping well must to be varying with time. Calculation according to Jacob formula showed that head drawdown started to take place at the model boundaries after pumping for 3.65 hours. The drawdown function can be derived from Equation (1), as in

$$
s= \begin{cases}0, & 0 \leq t<3.65 \\ 2.34 \ln t-2.95, & 3.65 \leq t \leq 50\end{cases}
$$

Temporally discretized the continuity function of the drawdown to a piecewise constant one, as shown in Figure 4. A broken line of discrete function $s^{\prime}(t)$ was used 
to approximately replace the curve of the original function $s(t)$, making sure the difference between the two adjacent constants of the function $s^{\prime}(t)$ was not greater than $0.5 \mathrm{~m}$. The function values are listed in Table 2 .

And then, divided the whole simulation time of the pumping test into 15 periods according to the function $s^{\prime}(t)$, in each period initial boundary heads of the model were set as a corresponding constant value, which could be get from the Equation (4) by replacing the values of function $s^{\prime}(t)$ listed in Table 2 for the drawdown. Then, the iterative calibration process started.

\subsection{Results}

After correcting the model parameters and boundary conditions repeatedly via the calibration processes of the pumping test model and recovery test model, the model parameters and boundary conditions were fixed on. Results showed that the calculated heads matched the observed data satisfactorily in both two models (Figure 5 and Figure 6); the mean absolute error between the calculated heads and observed data of pumping test simulation was $0.694 \mathrm{~m}$, and recovery test simulation $0.655 \mathrm{~m}$; both variances were less than $5 \%$. Furthermore, the coefficient of transmissibility was $5.3 \mathrm{~m}^{2} / \mathrm{d}$; it was close to the results of field tests $\left(5.7 \mathrm{~m}^{2} / \mathrm{d}\right)$.

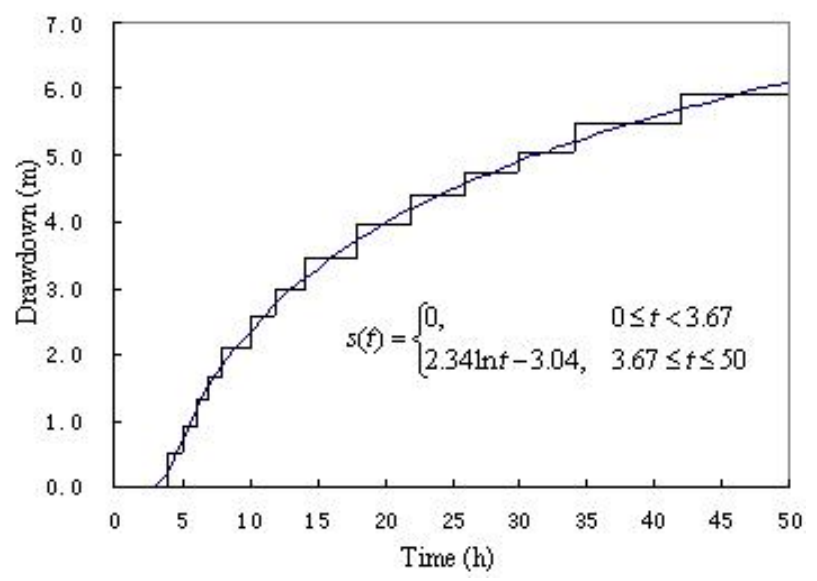

Figure 4. The curves of function $s(t)$ and function $s^{\prime}(t)$.

Table 2. The values of function $s^{\prime}(t)$.

\begin{tabular}{cccccc}
\hline $\begin{array}{c}t \\
(\mathrm{~h})\end{array}$ & $\begin{array}{c}s^{\prime}(t) \\
(\mathrm{m})\end{array}$ & $\begin{array}{c}t \\
(\mathrm{~h})\end{array}$ & $\begin{array}{c}s^{\prime}(t) \\
(\mathrm{m})\end{array}$ & $\begin{array}{c}t \\
(\mathrm{~h})\end{array}$ & $\begin{array}{c}s^{\prime}(t) \\
(\mathrm{m})\end{array}$ \\
\hline $0-4$ & 0 & $8-10$ & 2.08 & $22-26$ & 4.39 \\
$4-5$ & 0.5 & $10-12$ & 2.56 & $26-30$ & 4.75 \\
$5-6$ & 0.91 & $12-14$ & 2.95 & $30-34$ & 5.07 \\
$6-7$ & 1.32 & $14-18$ & 3.44 & $34-42$ & 5.47 \\
$7-8$ & 1.66 & $18-22$ & 3.96 & $42-50$ & 5.91 \\
\hline
\end{tabular}

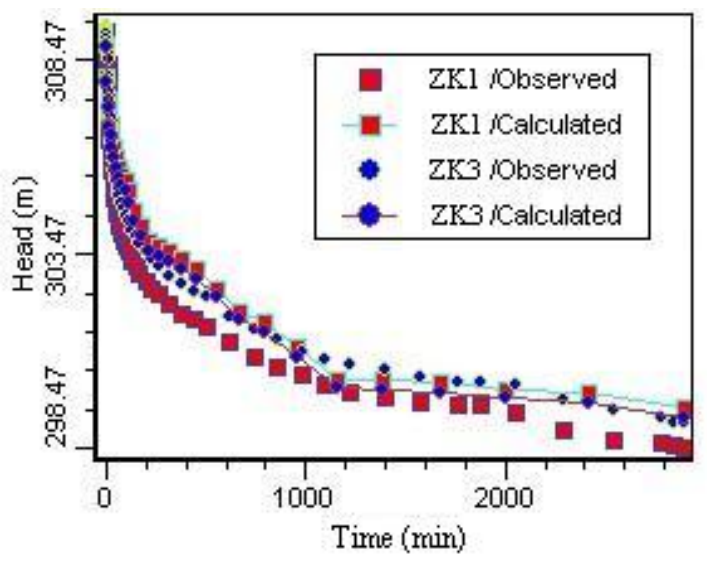

Figure 5. The results of calculated heads matched to observed heads of the pumping test model.

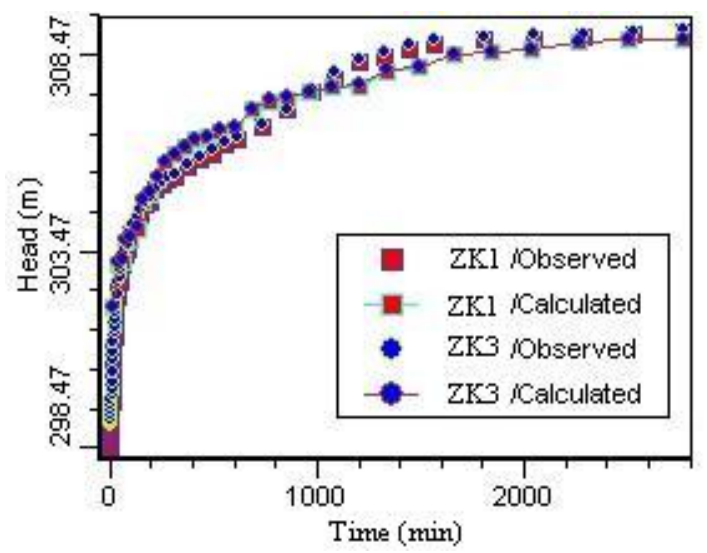

Figure 6. The results of calculated heads matched to observed heads of the recovery test model.

\section{Conclusions}

The boundary condition is one of key factors influencing the reliability of groundwater model. In case of artificial boundary conditions are needed, they should be set reasonably using as much field investigation data as we can get, otherwise, it is prone to cause great distortion to the truth and make the model worthless. Study results show that the method introduced in this paper can be a feasible choice to set artificial boundary conditions of the groundwater model.

\section{Acknowledgements}

Thanks for the fund of the Major State Basic Research Development Program of China (973 Program) (No. 2012CB723101).

\section{REFERENCES}

[1] H. R. Zhang, "Unsteady Groundwater Flow Theory Development and Application,” Geology Publishing House, 
Beijing, 1975, pp. 1-8.

[2] H. R. Zhang, "Groundwater Hydraulics Development," Geology Publishing House, Beijing, 1992, pp. 1-10.

[3] E. M. Labolle, A. A. Ahmed and G. E. Fogg, "Review of the Integrated Groundwater and Surface Water Model (IGSM)," Ground water, Vol. 41, No. 2, 2003, pp. 238-246. doi:10.1111/j.1745-6584.2003.tb02587.x

[4] L. H. Wei, L. C. Shu and Z. C. Hao, "The Present Situation and Development Tendency of Groundwater Flow Numerical Simulation,” Journal of Chongqing University, Vol. 23, 2000, pp. 50-52.

[5] J. H. Ding, D. L. Zhou and S. Z. Ma, “The State-of -Art and Trends of Development of Groundwater Modeling Software Abroad," Site Investigation Science and Technology, No. 1, 2002, pp. 37-42.

[6] L. C. Xu, "Introduction to Common Software Products Modeling Groundwater," Uranium Mining and Metallurgy, Vol. 21, No. 1, 2002, pp. 33-38.

[7] H. Q. Qu, S. Zeng and H. L. Liu, "Research Status and
Development of Numerical Simulation of In-situ Leaching of Uranium," Sci-tech Information Development \& Economy, Vol. 21, No. 9, 2011, pp. 177-180.

[8] Y. Q. Xue, "Present Situation and Prospect of Groundwater Numerical Simulation in China," Geological Journal of China Universities, Vol. 16, No.1, 2010, pp. 1-6.

[9] W.X. Lu, "Approach on Boundary Condition in Numerical Simulation of Groundwater Flows,” Journal of $\mathrm{Hy}$ draulic engineering, No. 3, 2003, pp. 33-36.

[10] Y. Y. Shen and Y. Z. Jiang, "Research on Disposal Method of Artificial Boundary Condition in Numerical Simulation of Groundwater Flow," Hydrogeology and Engineering Geology, No. 6, 2008, pp. 12-15.

[11] De lange W. J. and A. Cauchy, "Boundary Condition for the Lumped Interaction Between an Arbitrary Number of Surface Waters and a Regional Aquifer,” Journal of Hydrology, 1999, pp. 261-262.

[12] Y. Q. Xue, “Groundwater Dynamics,” Geology Publishing House, Beijing, 1997, pp. 45-95. 